\title{
LA CATEQUESIS EN EL CONTEXTO DE LANUEVA EVANGELIZACIÓN
}

DOI: https://doi.org/10.52039/seminarios.v60i2010.224

RINO FISICHELLA*

INTRODUCCIÓN

La temática que se esconde dentro de los dos términos en cuestión -nueva evangelización y catequesis- ha sido afrontada diversas veces, en sedes prestigiosas y en documentos que muestran la historia de la catequesis. Por nuestra parte, el objetivo que nos proponemos es el de evidenciar la problemática subyacente y los posibles recorridos que se podrían delinear en un próximo futuro. Me agrada situar estas consideraciones en el marco de la Evangelii nuntiandi (EN) de Pablo VI, porque de hecho expresa el enfoque de la problemática en el inmediato postconcilio: "Un camino que no se puede eludir en la evangelización es el de la enseñanza de la catequesis. La inteligencia, sobre todo la de los niños y adolescentes, tiene necesidad de aprender, mediante una enseñanza religiosa sistemática, los datos fundamentales, el contenido vivo de la verdad que Dios ha querido transmitirnos y que la Iglesia ha intentado expresar de modo cada vez más rico, en el curso de su larga historia. Nadie dudará que esta enseñanza deba ser impartida para construir hábitos de vida cristiana y no solamente para permanecer en la mente. Ciertamente, el esfuerzo de evangelización traerá un gran provecho, en el plano de la enseñanza catequética» (EN 44).

Para entrar más directamente en relación a este texto programático no está mal recordar, en primer lugar, el contexto dentro del cual se desarrolla la reflexión de la Exhortación apostólica. El Papa, en efecto, distinguía algunos caminos privilegiados dentro de los cuales era necesario desarrollar la obra de evangelización. La atención se ponía sobre «cómo evangelizar» (En 40).

Él ponía, ante todo, el testimonio como primer signo de toda obra evangelizadora ${ }^{2}$. Es en este contexto donde se sitúa la expresión que se ha hecho paradigmática: «El hombre contemporáneo escucha con más gusto a los testigos que a

* Relación de monseñor Fisichella en el Congreso Internacional de Catequesis.

1. «Nos baste, en esta reflexión, recordar algunas vías que, por una u otra razón, han tenido una importancia fundamental» (EN 40).

2. «El testimonio de una vida auténticamente cristiana, abandonada en Dios en una comunión que nada debe interrumpir, pero igualmente entregada al prójimo con un celo sin límites es el primer medio de evangelización» (EN 41). 
los maestros, o si escucha a los maestros, lo hace porque son testigos» (En 41). No obstante, añadía que el anuncio era la condición determinante para la eficacia de la evangelización, aunque recordaba a continuación que era importante tener en cuenta la nueva cultura en el horizonte que ocupaba cada vez más espacio, y de la cual hoy nosotros veíamos los resultados. El Papa hablaba de la «cultura de la imagen» que predominaba sobre la de la palabra ${ }^{3}$. Sobre este escenario del anuncio, Pablo VI ponía el primado de la Palabra de Dios. Sobre todo en el ámbito de la liturgia subrayando hasta qué punto era esencial prestar la debida atención a la homilía para que recuperase su plena eficacia pastoral precisamente de cara a la evangelización ${ }^{4}$.

La reconstrucción de este contexto permite ver la catequesis inserta en el interior del servicio debido en primer lugar a la Palabra de Dios que viene anunciada, como una etapa peculiar de la evangelización. Olvidar este aspecto es desnaturalizar la misma catequesis y convertirla en no conforme al plan pastoral de la Iglesia y, por tanto, empobrecer el impulso de evangelización.

Esta dimensión, sin embargo, lleva a resaltar un ulterior aspecto que ve la primacía de la evangelización sobre la catequesis. La cosa puede parecer obvia pero trae consigo algunas consecuencias que merecen ser consideradas. Ante todo, el hecho de que si se modifica el concepto fundante de consecuencia también el segundo término de se transforma en un proceso de cambio. Pensar, por tanto, que la Iglesia emprenda un camino de nueva Evangelización y que la catequesis permanezca con las mismas características del pasado -si bien reciente- es un peligro a evitar. La relación que lleva a unir «nueva Evangelización» y "catequesis», conlleva necesariamente la exigencia de una renovada interpretación del proceso catequético leído a la luz de la nueva evangelización; en consecuencia como instrumento al servicio de la comunidad cristiana para encontrarse los creyentes y cuantos andan en busca del sentido de la vida. Para los primeros no habrá que sobrevalorar la exigencia de una catequesis que se exprese y desarrolle en clave misionera para hacer comprender a cuantos son parte activa de la comunidad cristiana, la exigencia de recuperar la fuerza del

3. «Sabemos bien que el hombre moderno, hastiado de discursos, se muestra con frecuencia cansado de escuchar y, lo que es peor, inmunizado contra las palabras. Conocemos también las ideas de muchos psicólogos y sociólogos, que afirman que el hombre moderno ha rebasado la civilización de la palabra, en estos tiempos ineficaz e inútil, para vivir hoy en la civilización de la imagen. Estos hechos deberían ciertamente impulsarnos a utilizar, en la transmisión del mensaje evangélico, los medios modernos puestos a disposición» (En 42).

4. «Además en un momento en el que la liturgia renovada por el Concilio ha valorizado mucho la «Liturgia de la Palabra», sería un error no ver en la homilía un instrumento válido y muy apto para la evangelización. Cierto que hay que conocer y poner en práctica las exigencias y posibilidades de la homilía para que ésta adquiera toda su eficacia pastoral. Pero sobre todo hay que estar convencido de ello y entregarse a la tarea con amor. Está inserta de manera singular en la celebración eucarística, de la que recibe una fuerza y vigor particulares, tiene ciertamente un puesto especial en la evangelización, en la manera en que el ministro sagrado expresa la fe profunda de quien predica y que está impregnada con su amor» (En 43). 
anuncio. Para los segundos, ésta pueble llegar a ser un verdadero instrumento de «anuncio»-a veces «primer anuncio»- para recibir progresivamente la novedad de la fe y su importancia para la vida. Para usar las palabras del Papa Francisco: «La acción de Cristo nos toca en nuestra realidad personal, transformándonos radicalmente, haciéndonos hijos adoptivos de Dios, partícipes de la naturaleza divina; modifica así todas nuestras relaciones, nuestra situación concreta en el mundo y en el cosmos, abriéndola a su misma vida de comunión. Este dinamismo de transformación propio del Bautismo nos ayuda a acoger la importancia del catecumenado, que hoy, también en las sociedades de antiguas raíces cristianas, en las cuales un número creciente de adultos se acerca al sacramento bautismal, reviste una singular importancia para la nueva evangelización. Es el camino de preparación para el Bautismo, por la transformación de toda la existencia en Cristo» (LF 42).

La Iglesia ha evangelizado siempre. Evangelizar no es una de tantas tareas que el Señor Jesús le ha confiado, es la misma naturaleza de la Iglesia. Sin evangelización no hay Iglesia. Lo drástico de la expresión evidencia la esencia de la cuestión teológica. A partir de la misión de evangelizar ha nacido en el reciente pasado la llamada a una «nueva evangelización» ${ }^{5}$, como responsabilidad que la Iglesia está llamada a asumir tras un clima cultural modificado que ve de modo especial a los países de antigua tradición cristiana sometidos a una radical trasformación. Lo que se puede constatar es la conciencia de nuestros contemporáneos de haber entrado ya en la fase de edad madura y por ello de haber alcanzado la libertad para ser autónomo y responsable en todas las condiciones personal, social y religiosa de su vivir. Esta condición se hace ahora más evidente por la complejidad de las relaciones que el mundo de hoy vive a la luz de la globalización y de la rapidez de informaciones por estar ya en un mismo tiempo de una a la otra parte del planeta. Las innumerables posibilidades de dominar y modificar la naturaleza, las cotidianas conquistas de la ciencia y de la técnica, unidas al pluralismo de opiniones ya de hecho incontrolables, lejos de haber robustecido a nuestros contemporáneos, los han debilitado fuertemente en su identidad. Paradójicamente, la conciencia de la mayoría de edad está obligada a conjugarse con la experiencia de precariedad. La multitud de informaciones y conocimientos en los que está metido lo desorientan en la busca de la verdad sobre su propia vida y su proyección en el futuro ${ }^{6}$.

El creyente no es inmune a este contexto cultural. Lo que no se deriva de él se coloca ante nuestros ojos. Aparece de modo evidente el distanciamiento de la fe bautismal que se expresa de muchas maneras: el analfabetismo religioso, también en creyentes que en la vida profesional ocupan puestos de relieve cultu-

5. Cf. R. Fisichella, La nuova evangelizzazione. Una sfida per uscire dall'indifferenza, Milano 2011.

6. Cf. K. Rahner, Ciencia y fe cristiana, Roma 1984, 165-169. 
ral; falta de identidad creyente, que encuentra verificación en comportamientos igualmente en claro contraste con la fe; indiferencia en la participación de la vida de la comunidad con la consiguiente pérdida del sentido de pertenencia a la Iglesia misma; visión relativista de los contenidos de la fe y la moral que prescinden de la perspectiva de la fe. Esto y más invita a verificar el estado de la fe en los bautizados en un contexto social y cultural que en el pasado estaba impregnado de fe cristiana y que hoy parece diluirse cada vez con más celeridad. Esta condición es mayormente visible en los Países de antigua tradición cristiana -y, desgraciadamente, no sólo en éstos- donde es fácil encontrase con personas que están impregnadas de cristianismo por la misma cultura en la que están insertos, pero que no tienen la valentía de hacer la elección de fe. La presencia en estos países muestra también a muchos que no están ni siquiera bautizados y muchos que, aunque bautizados, no sienten la exigencia de confirmar la fe o de recibir el matrimonio cristiano.

Una de las tareas de la nueva evangelización consiste en primer lugar en el reavivar la fe de los cristianos que están más cerca de la comunidad. Con frecuencia, en efecto, su fe parece llegada como la brasa del fuego que arde, pero no es una llama viva capaz de dar base a la existencia. Por diversos motivos, se ha convertido en una fe débil, para muchos incluso irrelevante para la vida, y tiene necesidad de un renovado impulso. Por este motivo la catequesis tiene directamente la tarea de encontrar métodos y contenidos que le permitan ser una etapa adecuada en este movimiento de nueva evangelización que la Iglesia ha emprendido, ante todo para interpelar a los cristianos en este tiempo.

La catequesis, como se sabe, marca un momento central en la vida de la Iglesia. Sólo mirando su evolución histórica, sería fácil demostrar hasta qué punto en las diversas épocas históricas ésta ha jugado un papel fundamental en la transmisión de la fe. Con la catequesis, en efecto, la Iglesia no sólo ofrece a los cristianos los frutos del desarrollo de la fe que crece en el transcurso de los siglos para una inteligencia cada vez más profunda del misterio. Junto a ésta, se ofrece a los fieles la posibilidad de robustecer la identidad que debe enfrentarse con las nuevas adquisiciones de la cultura y del espíritu de tiempo para estar en disposición de ofrecer una respuesta cargada de sentido. Difícilmente se pueden encontrar otros ámbitos en la vida de la Iglesia donde sea posible verificar juntos el desarrollo de la doctrina, la praxis pastoral de la comunidad y el crecimiento de cada fiel como lo permite la catequesis. Ella, en algunos aspectos, deviene una síntesis en torno a la cual se expresa la vida de la Iglesia. La fuerza de la catequesis, en efecto, depende del espesor teológico que sabe mediar en la comprensión de los contenidos de la fe, en las motivaciones que sostienen la vida sacramental encontrando en la liturgia el espacio más adecuado para hacer hablar al mismo misterio (mistagogía) y, en fin, en ofrecer su valiosa contribución para que el testimonio de la caridad no sea incomprendido, sino conservado en su cauce de amor gratuito que a todos va a ayudar sin esperar nada a cambio. 
Repensar la catequesis, por tanto, comporta revisar su vínculo original con la evangelización para comprender el papel a desarrollar en la tarea de reforzar la fe de los creyentes en este peculiar momento de nuestra historia.

Explicitar la dimensión misionera de la catequesis, sin embargo, no es retórica, sino responsabilidad que compete a cuantos han asumido de diversos modos este ministerio en la comunidad. Esto conlleva la atención, pero suficientemente reforzada, de la formación para cuantos son llamados a este servicio. Una formación que no separa los contenidos de la vida, sino que la sitúa en la raíz propia de todo bautizado de tomar conciencia del compromiso para la evangelización. Lo que comporta el conocimiento de los contenidos de la fe, de modo proporcionado y progresivo al desarrollo personal, expresado con el testimonio de vida. Deberemos preguntarnos, en este contexto, cuánto cuidado pone la actual catequesis en comunicar la conciencia de la vida nueva que brota del bautismo y que en Cristo hace hijos de Dios. Es aquí, en efecto, donde se inserta la exigencia de hacer comprender la novedad cristiana. Uno de los temas centrales de la nueva evangelización se sitúa precisamente en el presentar la novedad que el encuentro con Cristo. El contexto cultural que vivimos parece impedir precisamente esta dimensión. El cristianismo es considerado como obvio, fruto de una contingencia histórica más o menos feliz, pero incapaz de influir en la vida de las personas de hoy. De hecho, la cuestión teológica que se compromete en dar razón de la novedad del cristianismo, confluye con la posibilidad de presentar una antropología capaz de mostrar la vida nueva de Cristo como cumplimiento de la búsqueda de sentido que el hombre realiza. La catequesis debería preparar y sostener este proceso, mostrando las razones que se hallan en la base del testimonio cristiano. El estilo de vida de los cristianos, permanece como la verdadera respuesta a estos interrogantes. Deberemos preguntarnos, pues, cómo es posible que un pequeño grupo de personas, en una ciudad multicultural como Antioquía, fuese capaz de hacerse conocer tanto que por primera vez los discípulos fueron llamados «cristianos» (cf. Hch 11,26) y hoy una realidad como mil doscientos millones de católicos vivan en el mundo sin suscitar al menos curiosidad por su estilo de vida.

Todo lo cual se hace ahora más urgente, si se piensa en los destinatarios de la catequesis que presentan un amplio abanico de perspectivas diversas. Tenemos una catequesis de carácter puramente sacramental que tiende a la educación cristiana básica que encuentra respuesta en los sacramentos de iniciación -que prácticamente se reduce a la primera comunión y confirmación-y que parece absorber toda la tarea de nuestra pastoral. Tenemos modelos de catequesis que se encuentran en diversas experiencia y se pueden recoger bajo el nombre de «catecumenado». No faltan catequesis así llamadas «permanentes» porque tienen la finalidad de conducir a los cristianos a una profundización y consolidación de la fe. Como se advierte, la diversificación si, por una parte, podría evidenciar la fragmentación, por otra, busca respetar las exigencias mismas de la fe que pide una inteligencia constante y una coherencia continua. 
Probablemente, en cuanto se refiere a la dimensión de nueva evangelización, deberíamos cuidar el momento de la transmisión de la fe. La exigencia de nueva evangelización parece nacer justamente del hecho de que se ha interrumpido la transmisión de la fe a partir de la pérdida de la importancia de la familia. Comprender las causas de este fenómeno que pone en grave crisis la fe es una tarea inaplazable. Junto a ello, en efecto, sería posible determinar qué respuesta positiva la Iglesia pretende emprender para dar forma y espesor a la pastoral y a la catequesis en particular. Sabemos ya que particularmente en Europa y en Norteamérica muchos se acercan a la fe por primera vez de adultos. La experiencia de estos años es rica, fecunda y con resultados positivos que merecen ser analizados para comprender la complejidad del fenómeno. Es igualmente verdad que para muchos de estos, el cristianismo llega como "primer anuncio» recibido según las diversas circunstancias de la vida. Estaremos totalmente comprometidos para que este anuncio se convirtiera en expresión del actuar de toda la comunidad cristiana que ha entendido la exigencia de recuperar con fuerza el espíritu misionero a menudo abandonado en los décadas pasadas, no sin consecuencias negativas. Cierto, este momento no es aún catequesis, sin embargo se puede fortalecer para estructurarse como un recorrido catequético de modo que la presentación del misterio de Cristo no sea fragmentaria sino unitaria en la sistemática propia de la comunicación de fe. La condición de crisis de fe que vive sobre todo Occidente y que ve una multitud de cristianos bautizados que, aun sin renegar de la fe, están cada vez más lejos del evangelio y de la comunidad, obliga a emprender nuevos caminos para no hacer inútil Pentecostés.

Si la comunidad se hace cargo de este "primer anuncio» esto significa que la misma comunidad debería ser capaz de delinear el recorrido sucesivo de un catecúmeno para no dejar a nadie a merced de sí mismo una vez recuperado el valor de la fe. Esto debería consistir en «profundizar, consolidar, nutrir, hacer cada vez más madura la fe» (EN 54). Éste sería un momento de gracia especial para los adultos, porque les conduciría progresivamente a la elección de la fe no como un hecho emotivo, sino como un compromiso que posee todos los rasgos para una elección libre y verdadera que se cumple conscientemente para confiar en el Señor. No se debería temer hoy presentar la radicalidad de la fe cristiana que es señal de una vida nueva ofrecida realmente con el Bautismo. Antes de cada expresión de seguimiento en el camino de los mandamientos y de las bienaventuranzas, es importante anticipar la conciencia de la vida de gracia que se nos regala. El don de la vida de Dios es don que se hace visible y se convierte en tarea para configurar la propia vida en Cristo. 